\title{
A "masculinização" da produção de leite
}

Reginaldo Sales Magalhães ${ }^{1}$

Resumo: O fortalecimento de organizações sociais que possibilitaram fazer da produção de leite uma atividade destinada ao mercado provocou profundas mudanças na divisão sexual do trabalho. A análise sociológica das trocas intradomiciliares nos estabelecimentos rurais familiares mostra que tradições culturais, diferenças de poder entre os gêneros e contextos sociais que ampliam diferenças de acesso aos mercados entre homens e mulheres são as bases sociais e culturais de uma hierarquia estruturada segundo sexo e geração, no qual as mulheres, especialmente as mais jovens, ocupam posições de grande desvantagem. Com o fortalecimento de cooperativas, a produção de leite passou a ocupar um lugar de destaque no provimento de recursos da família, mas o domínio da atividade foi deslocado para o controle masculino. Esse foi um dos resultados não esperados da forma como as organizações conduziram o processo de modernização da produção e de reestruturação dos mercados, que reforçaram ainda mais o domínio masculino sobre a produção familiar e um aumento das desigualdades de gênero no acesso aos recursos.

Palavras-chaves: Gênero, mercados, sociologia econômica.

Classificação JEL: Z1, Z13.

${ }^{1}$ Especialista em políticas agrícolas pela Unicamp, mestre e doutorando em Ciência Ambiental na USP. E-mail: regi.magalhaes@uol.com.br 


\begin{abstract}
The strengthening of social organizations that made it possible for dairy production to become a market-driven activity has brought about deep changes in the sexual division of labour. The sociological analysis of the changes in family-farming intra-household roles shows that cultural traditions, gender-related power gaps, and social contexts that further deepen differences in market access between men and women are the social and cultural foundations of a hierarchy structured according to sex and generation, where women, especially the youngest, occupy greatly disadvantageous positions. With the strengthening of cooperatives, dairy production began to occupy a rather important role in providing resources to the household, yet the control over the activity shifted to men. This was an unexpected outcome of how the organizations conducted the process of modernizing the production and restructuring the markets, which further reinforced male control over the household production and increased the gender gap with regard to access to resources.
\end{abstract}

Key-words: Gender, markets, economic sociology.

JEL Classification: Z1, Z13.

\title{
1. Introdução
}

Para os agricultores familiares de origem italiana da região Sudoeste do Paraná, a produção de leite é uma atividade tradicionalmente feminina ${ }^{2}$. Porém, um importante paradoxo atinge as organizações da agricultura familiar ao promover o desenvolvimento da produção e do mercado de leite. A formação das cooperativas de leite, apesar de melhorar a vida do conjunto das famílias, não conseguiu ampliar as liberdades das mulheres. Pelo contrário, manteve a reclusão feminina ao âmbito doméstico, acentuando, assim, as desigualdades entre homens e mulheres. Segundo diversas lideranças sociais e pesquisadores, com o aumento da importância econômica da produção de leite para as famílias, os homens passaram a exercer o domínio sobre a atividade. O objetivo desse artigo é discutir porque os homens passaram a controlar a produção de leite.

${ }^{2}$ Essa é um fenômeno específico, mas não é único. Na França, segundo relato de Maria José Carneiro (1998), ocorreu processo semelhante. Mas em outros grupos sociais na mesma região, a identificação da produção de leite com o trabalho feminino não é homogênea, nem estática. Fala-se na região que "quando se vê um homem tirando leite, ou ele é alemão ou é do sindicato". 
A ampliação do acesso aos mercados vem provocando uma forte mudança não só nas relações sociais do território, como também nas relações sociais no ambiente intradomiciliar. Tais mudanças podem ter impacto profundo numa distribuição de recursos que é, tradicionalmente, muito desigual entre os membros das famílias. A divisão do trabalho nas unidades de produção familiar provoca uma masculinização não só da produção, mas de todo o meio rural. Aqui um exemplo dentre as várias condições sociais que fazem do meio rural um lugar menos propício para as mulheres, especialmente das mais jovens, fazendo com que o meio rural torne-se predominantemente cada vez mais idoso e masculino (Camarano e Abramovay, 1999). Analisar as relações de gênero nesta atividade específica ajudará a compreender os motivos da persistência da desvantagem feminina ainda intensamente presente no mundo rural.

Apesar da importância social e política do tema, mesmo a sociologia econômica, que se justifica exatamente pela sua capacidade de interpretação das relações sociais que estão na base das transações econômicas, tem dado pouca atenção às relações entre gênero e economia. Ruth Milkman e Eleanor Townsley (1994) observaram na principal publicação da área, o Handbook of Economic Sociology, o quanto a sociologia econômica é ainda pouco sensível à dimensão de gênero. Ainda que exista de fato certa divisão de trabalho determinada pelo gênero na própria sociologia econômica, Viviana Zelizer (2000), numa análise sociológica da Sociologia Econômica, mostra que as questões relacionadas ao poder e à desigualdade são ainda minoritárias frente a uma agenda de pesquisa menos crítica ao mainstream econômico. Mais do que a existência de uma maioria masculina entre sociólogos econômicos, são as abordagens predominantes na sociologia econômica e, principalmente, na economia que contribuem para o pouco interesse dado ao tema neste campo de pesquisas (Swedberg, 2004).

A crítica de Zelizer (2000) à relação entre gênero e economia predominante nas correntes da sociologia econômica mais próximas ao mainstream da economia é, na verdade, um questionamento aos pressupostos metodológicos presentes na análise dos fenômenos econômicos. A mesma crítica é feita por autores da Economia Feminista, uma abordagem crítica da economia organizada na International Association for Feminist Economics, que busca construir um ponto de vista feminista para as questões econômicas. Segundo Julie Nelson (1998) 
a abordagem individualista da ação econômica ignora a natureza social das ações individuais e das relações de poder e coerção no interior das famílias. As críticas feministas à economia neoclássica destacam o auto-interesse como uma visão androcêntrica das suas bases teóricas. Adotando como pressuposto que as utilidades são determinadas exogenamente, a abordagem utilitarista impossibilita uma comparação interpessoal dos interesses.

Gary Becker (1991), autor da mais expoente e influente abordagem científica sobre as famílias baseada na escolha racional, aplica os pressupostos teóricos da economia neoclássica - comportamento maximizador, equilíbrio de mercado e preferências estáveis - para explicar decisões individuais no âmbito familiar, tais como escolher um cônjuge, ter e cuidar de um filho ou a alocação do tempo, e as relações entre essas escolhas e a produção de riqueza. Em seu "Tratado sobre a família" (Treatise on the family), Gary Becker (1991) compara a família a uma pequena fábrica que combina tempo e bens de mercado para produzir mais mercadorias que diretamente entram na sua função de utilidade. Assim, todas as atividades desempenhadas no domicílio, como o tempo despendido em cozinhar ou arrumar a casa, e até mesmo o tempo de dormir e ouvir música, são consideradas funções da produção de mercadorias. Elogiado pelo reconhecimento daquilo que é considerado o não-trabalho feminino não fornece, porém, instrumental analítico suficiente para uma análise concreta da situação das mulheres no ambiente da produção doméstica. $\mathrm{O}$ modelo de escolha coletiva familiar, de Gary Becker, conhecido como "modelo altruístico", considera os domicílios como indivíduos, "caixas pretas", nas quais os indivíduos possuem preferências homogêneas e as escolhas de cada indivíduo buscam maximizar não só suas utilidades individuais, mas, simultaneamente, as utilidades coletivas (Pollak, 2002). Assim como nos pressupostos neoclássicos do mercado, a maximização do bem-estar de cada indivíduo levaria ao melhor resultado familiar possível. A conclusão política dessa abordagem é que são irrelevantes as influências externas na alocação de recursos no interior das famílias. Por que então, as mulheres se queixam de desvantagens com relação aos homens?

Por outro lado, abordagens sociológicas consideram que a gestão das economias familiares é o resultado de constantes conflitos de interesses e acordos entre os seus membros. As diferenças no comportamento financeiro entre homens e mulheres são características culturais que 
exercem influência importante na forma de organização da gestão financeira das famílias. São, porém, diferenças que variam significativamente entre grupos sociais com características culturais distintas. Relações sociais são determinantes para a formação dos interesses individuais e para as condições de acesso e controle de recursos. Diferentes formas de inserção na sociedade e no trabalho geram diferenças de interesses, de acesso e de controle entre homens e mulheres. As defasagens entre homens e mulheres nos processos econômicos podem ser explicadas pela existência de diferentes interesses e de assimetrias na posse de recursos disponíveis entre cada membro dos núcleos familiares. É o pressuposto a partir do qual Swedberg (2003) propõe a análise das relações entre gênero e economia. Para England e Folbre (2005), a distribuição dos fluxos de recursos entre os cônjuges, principalmente dinheiro e tempo, deveria ser um dos focos centrais da abordagem sociológica dos fenômenos econômicos ${ }^{3}$.

Os dados empíricos discutidos nesse trabalho são resultados da pesquisa de campo realizada por Daniela Celuppi e Maria Helena Panzer, do Sindicato dos Trabalhadores Rurais de Francisco Beltrão e estudantes da UERGS (Universidade do Estado do Rio Grande do Sul), sob orientação de Ricardo Abramovay, Mônica Shroeder e Reginaldo Magalhães, como parte do projeto de pesquisa "As forças sociais dos novos territórios: o caso da Mesorregião Grande Fronteira do Mercosul", da Fipe (Fundação Instituto de Pesquisas Econômicas), Departamento de Economia da USP (Universidade de São Paulo) e Rimisp (Centro Latinoamericano para el Desarrollo Rural ${ }^{4}$ ). As entrevistas foram realizadas com 50 famílias produtoras de leite e moradoras no Assentamento Missões e na comunidade Linha Formiga, ambos no município de Francisco Beltrão (PR), no período de outubro e novembro de 2005.

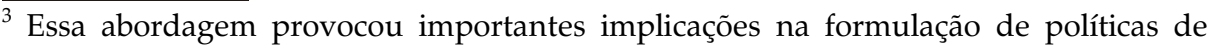
desenvolvimento. Pesquisa realizada junto a famílias de baixa renda da Bolívia, Brasil, Chile, Nicarágua e Peru (Birdsall, 1995) mostrou que as mulheres tendem a gastar mais em saúde, educação, alimentação e água potável. Ou seja, o aumento do poder financeiro das mulheres contribui para ampliação do capital humano. A idéia é que o maior acesso das mulheres ao crédito amplia os investimentos na educação, na saúde e na alimentação dos filhos. Muitas políticas governamentais de distribuição de renda se orientam por esta conclusão, estabelecendo regras de acesso aos programas para que eles atinjam de forma mais eficaz seus objetivos fundamentais.

${ }^{4}$ Esta pesquisa faz parte do projeto "Movimientos Sociales, Gobernanza Ambiental y Desarrollo Territorial Rural", coordenado pelo Rimisp-Centro Latinoamericano para el Desarrollo Rural: http://www.rimisp.cl/seccion.php?seccion $=308$
} 


\section{As trocas intradomiciliares}

A unidade entre negócio e família é um dos traços mais importantes da agricultura familiar. Segundo Alexander Chayanov (1925/1986), essa é uma característica de todo empreendimento que se sustenta sobre o trabalho familiar e cujo resultado econômico destina-se às necessidades básicas da família. A distribuição dos recursos tem um fluxo contínuo, integrado e inseparável entre domicílio e atividade produtiva. É o que ocorre especialmente com os recursos financeiros (Magalhães, Bittencourt e Abramovay, 2003) que, independente da fonte, seja da própria atividade agrícola, de salários, de aposentadorias, de transferências de outros membros da família ou de programas governamentais, são administrados, normalmente, num único caixa, servindo ao mesmo tempo às necessidades produtivas ou às necessidades de consumo das famílias. A ausência de separação entre as finanças produtivas e as finanças domésticas exige uma abordagem integrada da vida financeira da agricultura familiar.

A vida financeira dos agricultores está constantemente submetida à incerteza e ao risco, seja por causa das oscilações nos resultados da atividade produtiva, provocadas por inúmeros eventos como secas, enchentes, doenças, etc., ou por causa dos riscos e incertezas da vida em geral (Rutherford, 1999). Como, na maioria dos casos, as receitas são sazonais, imprevistos como doenças, desemprego, viagens, etc., fazem com que os agricultores tenham que manter poupanças preventivas (Zeller, 1997). Estas várias situações da vida cotidiana exigem disponibilidades emergenciais de dinheiro. A liquidez dos ativos da família é uma das estratégias de gestão dos recursos familiares. Como grande parte da poupança dos agricultores é não-monetária, como animais, alimentos, insumos, etc., a necessidade repentina de dinheiro faz com que os agricultores tenham que se desfazer de seus ativos, muitas vezes em situações com preços desfavoráveis. Tais características tornam a vida financeira dos agricultores uma constante tentativa de fechar as duas pontas do ano. Como muitas vezes as necessidades de recursos são maiores que os recursos disponíveis no núcleo familiar, o endividamento é uma das principais estratégias de sobrevivência no meio rural. Essa é uma das principais conclusões do trabalho "Laços financeiros na luta contra a pobreza" (Abramovay et alli, 2004). 
Compreender as diferenças de gênero na gestão dos recursos financeiros tem sido uma preocupação crescente nos estudos de microfinanças. A sistematização destes estudos, realizada por Luis Eduardo Amaya Mesa (1999) para a FAO (Organização das Nações Unidas para Agricultura e Alimentação), se organiza em torno de três questões básicas. Existem demandas financeiras que são específicas para homens e mulheres? Estas diferenças se expressam, sobretudo, na diferenciação entre as finanças das atividades produtivas, geralmente conduzidas pelos homens e as finanças das atividades domésticas, geralmente controladas pelas mulheres. Os comportamentos financeiros se diferenciam em função das identidades e dos papéis sociais de gênero? Neste caso, nota-se maior compromisso em honrar os pagamentos de empréstimos e maior propensão a poupar por parte das mulheres. As redes de relações sociais se diferenciam entre homens e mulheres? Os trabalhos empíricos revelam maior acesso masculino aos serviços bancários e maior participação feminina em atividades financeiras informais (caixinhas, consórcios, campanhas de solidariedade e fiado no comércio). Segundo Swedberg (2003), existe uma relação entre gênero e economia e as diferentes formas de inserção, masculina e feminina, nos mercados podem ser compreendidas buscando-se as especificidades em termos de interesses individuais e controles de recursos. Como diferentes formas de inserção na sociedade e no trabalho geram diferenças de interesses, de acesso e de controle entre homens e mulheres e como as economias familiares são resultados dos conflitos de interesses e de acordos entre os seus membros, é necessário conhecer cada contexto social e como tal contexto gera diferenças de acesso aos mercados entre homens e mulheres (Magalhães, 2004).

Em algumas situações existe a separação de recursos de determinadas fontes que são destinados para usos específicos. É o caso especialmente do dinheiro da aposentadoria, sobretudo no caso da aposentadoria da mulher. A possibilidade de a mulher passar a dispor de recursos sob seu controle pessoal, amplia seu poder de decisão sobre o uso, fazendo opções diferentes daquelas que o marido adota quando tem o controle sobre os recursos da família. Nas entrevistas com agricultoras, muitas dizem que com a aposentadoria, é a primeira vez que vêem dinheiro. Mesmo assim, a "fungibilidade" é ainda uma característica fundamental dos fluxos financeiros nas unidades de produção familiar. 
A mesma fluidez no uso do dinheiro, como será citada a seguir, ocorre com a gestão do trabalho e do tempo livre. Neste caso, acrescenta-se, ainda, à distribuição do tempo e do trabalho familiar entre as várias atividades domésticas e produtivas, o recurso ao uso de mão-de-obra externa, através da contratação eventual ou da troca de serviços com pessoas que não fazem parte da unidade familiar ou a realização de serviços externos por parte de membros da família, em situações eventuais ou contínuas.

As habilidades para planejar as finanças pessoais e familiares, para manejar diferentes serviços financeiros, são adquiridas por meio de processos educativos. $\mathrm{O}$ acesso a essas informações e conhecimentos pode ser obtido através do ensino escolar, de campanhas educativas, na experiência obtida no relacionamento com bancos e comércio, ou por trabalhos educativos oferecidos por organizações. Na agricultura familiar, tal aprendizado se dá, especialmente através da experiência e da educação familiar. A relação financeira entre pais e filhos e a participação dos jovens e crianças nas decisões financeiras das famílias é também fundamental para a formação de um comportamento financeiro mais responsável entre jovens. É a conclusão de duas pesquisas, uma realizada com estudantes universitários de Portugal e outra com famílias da Inglaterra, pela Nestlé, em 2001. A possibilidade, desde a infância de gerir pequenas quantias de dinheiro e despesas pessoais é uma das formas mais importantes de formar uma cultura poupadora e responsável na vida adulta. A pesquisa da Nestlé, "Money in the contemporary family", mostra que a escola exerce também papel fundamental na educação financeira dos jovens.

Os jovens da área rural são ainda mais que as mulheres submetidos a uma estrutura de hierarquia que limita profundamente o acesso e o controle sobre recursos financeiros. Embora haja maior democratização dos espaços de participação nas relações familiares, os jovens têm pouco poder de decisão e pouca autonomia na gestão do dinheiro. Assim como na pesquisa sobre a sucessão hereditária, coordenada por Abramovay (2003), os filhos têm que pedir dinheiro aos pais toda vez que precisam. Nas famílias entrevistadas em Francisco Beltrão, a grande maioria dos jovens, independente da idade que tenham ${ }^{5}$ e do trabalho que exerçam na propriedade, precisa pedir dinheiro aos pais para todas as suas necessidades.

\footnotetext{
${ }^{5} \mathrm{Na}$ cultura rural da região, são jovens os solteiros que residam na casa dos pais.
} 
A autonomia dos jovens é conquistada apenas quando possuem um salário vindo do trabalho fora da propriedade dos pais - é esse inclusive um dos principais motivos do desejo dos jovens de sair de casa e da área rural. Na hierarquia estruturada segundo o sexo e a geração, são as mulheres jovens que ocupam as posições mais inferiores. A impossibilidade de ter acesso à terra no processo sucessório (Mello et alli, 2003) desqualifica ainda mais as jovens na sua relação com a terra e com os resultados do trabalho familiar. A construção social da identidade feminina supõe uma relação de dependência e submissão, fazendo com que as jovens permaneçam encerradas ao seu destino de reprodução das relações de esposa e mãe. As possibilidades de uma vida autônoma são viáveis apenas se tiver acesso a um salário fora da unidade familiar. A impossibilidade de reprodução da vida familiar com os recursos oriundos exclusivamente da produção no estabelecimento, aliada a emergência de valores centrados na realização individual é que vem abrindo oportunidades de estudo e de ocupação profissional e, com isso, a maior autonomia das mulheres jovens.

$\mathrm{Na}$ agricultura familiar não é possível separar as transações econômicas intradomiciliares das hierarquias de gênero e de geração que se estabelecem entre os membros de um núcleo familiar, fazendo com que mudanças no nível produtivo provoquem mudanças nas relações de gênero (De Grandi, 2003). A distribuição do dinheiro, do trabalho e do tempo segue determinadas regras. O primeiro e mais profundo princípio de organização das regras da gestão econômica é o valor simbólico da família.

Para compreender o sentido das trocas existente no interior do universo familiar é preciso levar em conta não apenas a racionalidade na gestão do dinheiro, do tempo e do trabalho. É necessário levar em conta a distribuição, na maioria das vezes profundamente desigual, dos diferentes capitais no interior da família. As diferenças nos interesses individuais entre homens e mulheres podem ser explicadas pelos processos históricos e culturais, ambientes institucionais, estruturas sociais de dominação, uma "ordem das coisas", aparentemente normal ou natural, que fazem perpetuar estilos de vida e visões de mundo que submetem homens e mulheres a uma estrutura hierárquica, sendo as mulheres colocadas em condições de desvantagem na maioria das sociedades e das famílias (Bourdieu, 2005). 


\section{A divisão sexual do trabalho}

A agricultura familiar é caracterizada por uma marcante divisão sexual do trabalho. A produção de leite é tradicionalmente uma atividade realizada pelas mulheres e o aprendizado das técnicas de produção são passadas das mães para as filhas. Porém, a passagem da produção de leite de uma atividade voltada à reprodução familiar para uma atividade destinada ao mercado pode provocar profundas mudanças na divisão sexual do trabalho. A divisão de funções entre os membros das famílias depende do grau de inserção da produção no mercado. Atividades produtivas mais destinadas ao consumo familiar são normalmente desempenhadas por mulheres, enquanto atividades de caráter comercial são normalmente desempenhadas por homens (Menache e Escher, 1996). Segundo lideranças de Santa Catarina, "quando a atividade era de subsistência os homens não participavam, mas quando ela passou a gerar renda eles se envolveram".

Na maioria das famílias, dentre o conjunto de operações necessárias à produção de leite, as mulheres se dedicam àquelas restritas ao âmbito interno das propriedades, enquanto que as relações externas, como venda da produção, compra de insumos, contato com técnicos, participação em reuniões e cursos, são, mais usualmente, executadas pelos homens. Segundo pesquisa realizada pelo Deser sobre as relações de gênero na produção de leite (Menache e Escher, 1996), alguns papéis são recorrentes: as notas fiscais de venda do leite eram emitidas em nome dos homens; são os homens também que recebem o pagamento mensal da venda do leite ou que fazem a contratação de financiamentos; mas quando o produto vendido é o queijo, são então as mulheres as responsáveis pela comercialização, visto que a relação com os "freteiros" nome dado ao encarregado de recolher o leite nas propriedades e importante agente de intermediação entre os produtores e as cooperativas ou indústrias - é uma função das mulheres, principalmente para venda de queijo. Por outro lado, o contato com os profissionais de assistência técnica, na grande maioria dos casos, era um papel masculino, assim como a participação em cursos e reuniões são também tarefas reservadas aos homens.

A reprodução dos modos de vida obedece a certa naturalização da continuidade das atribuições femininas e masculinas (Mello et alli, 2003). Quando se pergunta aos homens e às mulheres agricultoras o porquê de 
determinada divisão do trabalho, eles e elas não conseguem encontrar outra justificativa senão "é assim porque sempre foi assim" (Celuppi e Panzer, 2005). Esta ausência de explicações racionais e a profundidade em que tais atitudes se inserem na vida e na mente dos indivíduos, faz parecer que tais fenômenos naturais não têm origem, nem história.

A força da tendência à naturalização dos fenômenos sociais e do determinismo biológico nas explicações das diferenças de comportamento feminino e masculino é muito grande, mesmo entre pesquisadores feministas. Brumer (2000), por exemplo, afirma que as ocupações femininas são definidas por suas capacidades naturais, como executar tarefas repetitivas, cuidar de várias tarefas ao mesmo tempo, docilidade, habilidades manuais ou outras características desse tipo. Longe de ser determinado por qualidades intrinsecamente femininas ou masculinas, como ingenuamente muitos tentam argumentar, a divisão do trabalho é um processo cultural. Os papéis sociais de homens e mulheres, as tarefas identificadas como masculinas ou femininas, são crenças sociais, sujeitos a variações históricas e culturais (Ferber e Nelson, 1993). O próprio surgimento do conceito de gênero é uma tentativa de ruptura com a naturalização da situação das diferenças sexuais, passando da determinação biológica para a determinação social das relações (Machado, 2000). Isso não quer dizer que as diferenças biológicas não tenham importância na formação das identidades e na definição dos papéis sociais, mas que as diferenças sociais são, sobretudo, a expressão de significados atribuídos pela humanidade à diferenciação anatômica e fisiológica entre os sexos (Buarque, 2003). Gênero é o significado social, culturalmente construído, das diferenças entre os sexos (Ferber e Nelson, 1993).

A divisão de trabalho muda quando o leite passa a ser uma atividade mais importante na renda familiar? Segundo a grande maioria das famílias entrevistadas, não. Mesmo tendo o leite apresentado uma importância crescente na renda familiar, para a maioria dos entrevistados não houve mudanças na forma como as responsabilidades de cada uma das atividades que compõem o ciclo produtivo do leite são atribuídas Existem aí aparentes contradições muito reveladoras da interpretação que os agricultores e as agricultoras fazem das suas atividades.

São os arranjos institucionais que determinam os papéis de gênero na sociedade e nas atividades produtivas. O efeito de mudanças de tecnologias sobre a divisão sexual do trabalho foi objeto de importantes trabalhos de pesquisa. A mecanização da produção de algodão no interior 
de São Paulo provocou alterações nos papéis de gênero nos sistemas de produção e na organização domiciliar (Panzuti, 2006). O acesso às novas tecnologias é condicionado pelas relações de gênero e a forma como a assistência técnica se relaciona com os homens e as mulheres reforçam a hierarquia de gênero na divisão de trabalho. Na pesquisa de campo em Francisco Beltrão, ficou claro que a relação com a assistência técnica e a participação nos cursos são funções predominantemente masculinas. As mulheres se relacionam com os extensionistas apenas quando o técnico visita a propriedade ou quando são realizadas reuniões na comunidade e, especificamente quando o conteúdo da assistência técnica ou da capacitação se refere ao processamento do leite, a uma atividade doméstica, ou à higiene e ordenha dos animais. O impacto de novas tecnologias na organização do trabalho não é, portanto independente das relações sociais. A mudança tecnológica na produção de leite analisada por Renata Menache (2004) em sete municípios do Paraná, não alterou a hierarquia entre os membros das famílias, mas mudou a posição relativa da atividade na unidade de produção. Passando a ocupar um lugar de destaque no provimento de recursos da família, a atividade passou para o domínio masculino.

Há no processo da divisão sexual do trabalho condicionamentos culturais que determinam a posição de cada indivíduo na propriedade e na família (De Grandi, 2003). São em espaços e atividades de domínio masculino ou feminino que se definem os papéis sociais de gênero. Maria José Carneiro (1998) mostra que a divisão de trabalho não se baseia numa oposição rígida entre masculino e feminino, pois as atividades masculinas contêm as femininas e vice-versa. No estudo etnográfico de agricultores da Zona da Mata nordestina, Beatriz Heredia (1984) divide a unidade familiar em dois espaços: a casa e o roçado. A casa e suas extensões, o terreiro, a horta e as áreas de criação animal são espaços onde se realizam atividades de responsabilidade feminina. $\mathrm{O}$ roçado, mesmo sendo o resultado do esforço conjunto da família, é o espaço onde se realizam atividades de responsabilidade masculina.

Quando se encontram fora do seu lugar de domínio, o trabalho realizado, seja por homens ou por mulheres, é sempre considerado uma ajuda, um não-trabalho (Maia, 2004). É assim que os agricultores interpretam a participação dos homens em atividades domésticas. Nas comunidades rurais de Francisco Beltrão, com certo constrangimento, tanto dos homens como das mulheres, se reconhece que os homens 
"ajudam" em tarefas como lavar louça ou arrumar a casa. Da mesma forma, os homens "ajudam" as mulheres na ordenha das vacas. As mulheres, por outro lado "ajudam" os homens na lavoura, no manejo do pasto e na manutenção das cercas, atividades consideradas masculinas. A atribuição de responsabilidades pode ser ainda mais complexa. Se o serviço na lavoura é a produção de alimentos para os animais, como milho ou produtos para silagem, a atividade pode ser considerada feminina, mas dificilmente as mulheres envolvem-se, mesmo na condição de ajudantes, na produção de soja (Celuppi, 2005).

A força física é, por exemplo, uma das explicações que o senso comum atribui aos diferentes papéis exercidos por homens e mulheres. Mas capacidades físicas são também influenciadas por aspectos sociais e culturais. Para Simone de Beauvoir (1949), é preciso que existam referências existenciais, econômicas e morais para que a noção de fraqueza possa ser concretamente definida. Isto ficou evidente na pesquisa realizada pelo Deser (Torrens, 1996), no Paraná, que mostrou o quanto a determinação dos papéis depende de realidades culturais específicas, a partir das quais, os significados de trabalho leve e de menor importância econômica, atribuídos às mulheres, e trabalhos pesados e de maior responsabilidade, atribuídos aos homens, são construções resultantes de distintos contextos sociais. É fundamental, portanto, compreender os processos sociais e culturais que bloqueiam a participação das mulheres nos diferentes campos de relações sociais subjacentes à produção, ao mercado e às organizações. No estudo sobre a divisão do trabalho entre agricultores familiares da Paraíba, Paulilo (1987) observou que o trabalho é leve ou pesado, dependendo de quem o realiza. No Vale do Jequitinhonha (MG), Maia (2004) observa que a qualidade do trabalho (pesado ou maneiro) são representações. Tanto é que com o processo de migração que se verificou na região estudada, o mesmo "trabalho pesado", que antes era desempenhado pelos homens, passou a ser considerado "trabalho leve" quando passou a ser assumido pelas mulheres (Maia, 2004).

Não são, portanto, as características do trabalho, a necessidade de força ou resistência física que define, na representação dos agricultores, $\mathrm{o}$ peso do trabalho, mas o trabalho se define como trabalho pesado se for uma atividade do domínio masculino e é leve se for uma atividade do domínio feminino. As diferenças anatômicas entre os sexos são mais justificativas das diferenças socialmente construídas do que determinantes da forma como os papéis são definidos (Bourdieu, 2005). 


\section{A mudança no controle da atividade}

É voz corrente na região dizer que quando o leite começa a dar lucro e se torna o produto principal, a atividade passa a ser controlada pelos homens. O mesmo se diz em outras regiões a respeito da produção de plantas medicinais e de outras atividades típicas do domínio feminino. A masculinização da produção de leite também ocorreu em municípios de Santa Catarina, onde os produtores se associaram para a formação de miniusinas de processamento de leite. Segundo De Grandi (1999), além de perder o controle sobre a gestão e os resultados da produção, as mulheres se sobrecarregaram com o aumento da produção de leite. Para essa e outra pesquisadora catarinense (De Grandi, 1999 e Paulilo, 2003), isso se justifica quando se observa que, apesar da grande importância das mulheres na produção leiteira, no momento em que se trata da profissionalização da produção, quem freqüenta os cursos de treinamento oferecidos pelos órgãos de extensão são os homens. A conseqüência mais negativa dessa mudança é que com a especialização na produção de leite, as mulheres perdem o controle sobre o dinheiro que antes recebiam na produção de leite não especializada (Paulilo, 2003).

Com a organização da Cooperativa de Leite da Agricultura Familiar6, em 2002, o leite passou a ser a principal atividade econômica dos agricultores familiares das duas comunidades pesquisadas, a Linha Formiga e o Assentamento Missões. Nas entrevistas realizadas nas duas comunidades de Francisco Beltrão, fica evidente para praticamente todas as famílias que, há dez anos, o leite era uma atividade de pequena importância na renda familiar; há cinco anos, o leite passou a ser uma atividade de pequena a média importância e, atualmente, é considerado uma atividade de média e grande importância para as receitas da unidade familiar de produção.

Questionários iguais foram aplicados em 50 famílias, sendo respondidos separadamente pelo homem e pela mulher de cada casal. Comparando as respostas de cada membro da família, as entrevistadoras relatam que tinham a impressão de terem entrevistado duas famílias distintas, devido à intensidade das diferenças de opinião entre homens e mulheres. Especialmente ao serem perguntados sobre quem é o

${ }^{6}$ Sobre a organização da cooperativa e o seu papel no mercado ver o artigo também de minha autoria: "Habilidades sociais no mercado de leite". 
responsável pela atividade, homens e mulheres apresentaram grandes divergências em suas respostas.

Se no passado a atividade era, sem dúvida, uma atividade feminina, o controle sobre a gestão da produção de leite é hoje, pelo menos na expressão social, objeto de disputa entre os casais. Para dois terços dos homens são eles próprios os responsáveis pela atividade, enquanto para um terço, o casal é conjuntamente responsável. Já nas respostas das mulheres, uma quinta parte admite que os homens sejam responsáveis pelo leite e outro tanto as mulheres, enquanto os dois terços restantes considera que a responsabilidade pela atividade é do casal ${ }^{7}$.

Além dos aspectos culturais já expostos no artigo, as formas como as organizações conduziram o processo de modernização da produção e de reestruturação dos mercados, bem como as formas como as organizações se relacionam com homens e mulheres podem ser uma das explicações para a masculinização da produção leiteira. Será visto neste artigo como se expressam as relações de gênero nas principais organizações dos agricultores familiares da região.

\section{A participação nas organizações}

A participação dos homens em organizações é significativamente maior que a participação de mulheres. Com exceção da Igreja, onde tanto homens como mulheres participam igualmente, nos sindicatos, associações comunitárias, associações de produtores, cooperativas de leite e cooperativas de crédito, a participação é predominantemente masculina. As mulheres também participam dessas organizações, mas em número expressivamente menor. Às mulheres está reservada apenas a participação nas organizações de mulheres e nas instâncias comunitárias dessas organizações.

Como as organizações não têm planos de ação que estimulem mudanças nos tradicionais papéis sociais de gênero, a participação das mulheres nas cooperativas é pequena. Uma pesquisa sobre relações de gênero nas associações de agricultores familiares, coordenada por João Torrens (2000) mostrou uma presença majoritariamente masculina nas organizações da agricultura familiar. Existe uma clara delimitação dos espaços de participação feminina. Na Linha Formiga e no Assentamento

\footnotetext{
As respostas não têm representatividade estatística, mas são exemplos de situações típicas que podem ser analisadas a luz das questões teóricas discutidas nesse artigo.
} 
Missões, as mulheres participam das reuniões que são realizadas nas comunidades, enquanto os homens participam das atividades realizadas nas sedes das organizações.

Cerca de metade das famílias entrevistadas afirmam que o contato com bancos e/ou cooperativa de crédito é feito pelo casal, enquanto que em um terço das famílias a penas o homem é responsável pela relação com os bancos. Segundo dirigentes da cooperativa de leite, é comum a ida do casal à sede do município, a cada quinze dias, para receber o pagamento pela produção de leite. Enquanto o marido vai à cooperativa verificar a situação da conta, conversar com o gerente e segurar a vaga na fila, a mulher recebe o cheque na cooperativa de leite. A obrigatoriedade da assinatura da mulher em contratos de financiamento é outro fator que provoca o envolvimento do casal e não exclusivamente do homem com os bancos. Por esse motivo, na maioria das famílias entrevistadas, o dinheiro da família é depositado nos bancos em contas conjuntas. O significado disso é que a mulher cumpre uma função auxiliar, ou seja, "ajuda" o marido numa tarefa cujo domínio é ainda essencialmente masculino.

$\mathrm{Na}$ relação com os mercados, se expressam importantes diferenças nos papéis sociais de homens e mulheres. A relação com o "freteiro" é tipicamente uma atividade feminina, mesmo nos estabelecimentos onde o leite é a atividade econômica mais importante. Sendo ela uma presença mais constante na casa, o contato diário fica sob sua responsabilidade um papel de grande importância, uma vez que é com esse agente que se estabelecem relações de proximidade e confiança essenciais para a estruturação do mercado. É com o "freteiro" que as famílias negociam os preços, por meio de quem são comprados insumos, é quem controla a qualidade do leite e é através dele que se transferem informações entre os produtores e as indústrias (Magalhães, 2005).

Devido ao grande poder centralizado nas mãos do "freteiro", a principal estratégia da cooperativa de leite (Claf, Cooperativa de Leite da Agricultura Familiar) foi deslocar essa relação e reduzir o papel desse agente no mercado. A cooperativa está restringindo o papel do "freteiro" apenas ao transporte de leite e as transações comerciais passam a ser feitas diretamente entre os produtores e as cooperativas, por meio do contato direto entre produtores e diretores, realizada na sede da cooperativa ou em reuniões nas comunidades. A ida às sedes das cooperativas é quase exclusivamente realizada pelos homens, e a participação nas reuniões promovidas pelas cooperativas é predominantemente masculina, 
enquanto que as mulheres participam, junto com seus maridos, apenas nas reuniões que as cooperativas realizam nas comunidades. Ou seja, a nova organização de mercado estabelecida pela cooperativa, em nome de uma maior autonomia dos produtores, deslocou o centro de negociação entre produtores e mercados, do domínio feminino para o domínio masculino.

O fortalecimento das organizações da agricultura familiar está sendo um importante processo de ampliação do poder de negociação dos produtores com os mercados e as políticas públicas. Porém, os métodos predominantes de organização privilegiam maior concentração de poder na mão dos homens que na das mulheres. Essa é uma importante contradição a ser enfrentada pelas organizações.

As organizações são constantemente pressionadas a adotar políticas de redução das desigualdades de gênero. Além das pressões da sociedade em geral, no acesso dessas organizações a recursos da cooperação internacional, especialmente, e, de forma menos intensa, dos órgãos públicos, existem explícitas regras que impõem a adoção de políticas para reduzir a discriminação das mulheres. Essa pressão vem surtindo efeitos importantes. A Federação dos Trabalhadores na Agricultura Familiar (Fetraf Brasil), da qual a região sudoeste do Paraná é uma das suas bases políticas e sociais mais importantes e influentes, adota uma política de cotas para a participação de mulheres. No seu congresso nacional de fundação, realizado em novembro de 2005, quarenta por cento dos delegados eram mulheres. Ainda mais significativa que essa expressiva e surpreendente participação feminina no congresso, foi a eleição de uma mulher para presidente nacional da organização.

Uma pesquisa realizada com os delegados do Congresso da Fetraf revela uma importante introdução do tema na agenda sindical ${ }^{8}$. A preocupação com as relações de gênero é expressiva entre os delegados. Apesar de a metade dos delegados considerar que hoje em dia as mulheres não são tão discriminadas, outra metade considera que as mulheres enfrentam problemas nas unidades de produção familiar por meio de excesso de trabalho, desvantagens na renda e menor poder de decisão sobre a gestão da propriedade. Com relação às políticas públicas, dois terços dos delegados consideram que as mulheres são discriminadas no acesso ao crédito e à terra. Mais da metade dos sindicatos presentes no Congresso da Fetraf (Federação dos Trabalhadores da Agricultura ${ }^{8}$ Foram entrevistados 161 delegados da região Sul do Brasil. Essa pesquisa fazia parte também do projeto "As forças sociais dos novos territórios: o caso da Mesorregião Grande Fronteira do Mercosul", da Fipe, Departamento de Economia da USP e Rimisp. 
Familiar) também adota políticas de cotas para a participação de mulheres nas diretorias e na escolha de delegados e representantes; quase metade organiza grupos de mulheres; cerca de um terço oferece cursos de capacitação para mulheres; e um quinto dos sindicatos participa de lutas por políticas públicas para mulheres. Resultado do estímulo à adoção de políticas contra a discriminação das mulheres nos sindicatos é que apenas dez por cento dos delegados no Congresso da Fetraf acham que as mulheres apresentam dificuldades para participar das diretorias dos sindicatos e das cooperativas.

$\mathrm{Na}$ pesquisa realizada sobre as cooperativas de leite da agricultura familiar (Magalhães, 2005), segundo os seus dirigentes, a existência de comissões de mulheres em alguns sindicatos contribui para algumas mudanças no padrão tradicional de discriminação social. Nas cooperativas mais estreitamente relacionadas aos sindicatos, há maior participação de mulheres nas reuniões, cursos e mesmo nas direções. Segundo uma diretora da Cooperativa de Leite da Agricultura Familiar de Santa Catarina, a cooperativa estimula que o casal participe de todas as atividades e decisões. Resultado disso é a participação de oito mulheres numa diretoria composta por 26 pessoas. $\mathrm{O}$ aumento da participação feminina ainda é tímido, porém, crescente, reflexo também de mudanças culturais, sociais e econômicas no conjunto da sociedade brasileira e, especialmente, de um conjunto de políticas públicas que atingem de forma diferenciada homens e mulheres do meio rural.

O problema é que o incentivo à participação das mulheres nas organizações e o efetivo aumento da participação feminina não se repercute em ações concretas que eliminem os principais bloqueios à ampliação da participação das mulheres nos mercados. As próprias dirigentes concordam que as propostas de ação das organizações se limitam a discursos demasiadamente genéricos que, apesar de já terem vivenciado os mesmos dramas familiares, há grande desconhecimento sobre as estruturas sociais que reproduzem a dominação masculina. Com tais limitações, as novas formas de organização reproduzem a mesma lógica do modelo tradicional que estabelece as antigas estruturas de divisão do trabalho masculino e feminino. Mulheres são estimuladas a exercer atividades que tradicionalmente fazem parte do domínio feminino. Mais do que isso, as organizações não criam canais de participação que viabilizem a ampliação do universo de relações sociais nas quais as mulheres estão inseridas. 


\section{6. $\mathrm{O}$ acesso das mulheres ao crédito}

A análise de uma situação oposta ao das relações de gênero na produção de leite pode ser uma estratégia útil para compreender melhor o problema. Um conjunto de políticas públicas no âmbito do Plano de Políticas para as Mulheres levado adiante por oito órgãos federais e governos estaduais vem apresentando impactos positivos bastante significativos. No MDA (Ministério do Desenvolvimento Agrário) foi criado em 2001 o Programa de Ações Afirmativas. A primeira medida foi a realização do programa de documentação de mulheres, uma ação do governo federal em parceria com as Secretarias de Segurança Pública dos estados. O resultado em 2004 foi a emissão de documentos para $80 \mathrm{mil}$ mulheres. Na política de reforma agrária, passou a vigorar, a partir de 2003, a obrigatoriedade de titularidade conjunta nos assentamentos de reforma agrária. Na política nacional de assistência técnica foram financiados diversos programas, no valor total de 1,3 milhão de reais, para capacitação de mulheres ou de temas relacionados à questão de gênero. Foram realizadas diversas pesquisas e oficinas para identificação dos principais entraves no acesso das mulheres às políticas públicas.

A mais expressiva ampliação ocorreu no crédito rural. O Ministério do Desenvolvimento Agrário (MDA) tornou obrigatória a emissão de Declarações de Aptidão ao Pronaf (documento emitido por sindicatos ou órgãos de assistência técnica que credencia os agricultores para o acesso ao crédito) em nome do casal. No Plano Safra 2003/04, foi criada uma linha de crédito exclusiva para mulheres, o chamado Pronaf Mulher. Para coordenar esse trabalho e monitorar os resultados, o MDA criou o grupo de trabalho Gênero e Crédito, que envolveu os movimentos sociais, organizações não-governamentais, órgãos de assistência técnica e bancos no conjunto de políticas adotadas para ampliar a participação de mulheres no Pronaf. Em sintonia com as mudanças na regulamentação, foi realizada uma série de atividades de divulgação e capacitação, chamadas de Cirandas do Pronaf.

A partir das safras de 2003/04, houve uma expressiva ampliação do acesso de mulheres ao Pronaf. O número de contratos de crédito efetivados por mulheres cresceu de $7 \%$, em 1999, para $17 \%$ na safra $2004 / 05$. O crescimento expressivo ocorreu nas duas safras seguintes, com uma ampliação de 227 mil financiamentos concedidos a mulheres, totalizando de 1,9 milhão de contratos. O Pronaf Mulher foi inexpressivo 
e contribuiu apenas com 2.486 novos contratos. Ou seja, o aumento da participação feminina não ocorreu no âmbito da sua cota, mas justamente onde teoricamente há concorrência entre homens e mulheres. $\mathrm{O}$ principal aumento do número de mulheres financiadas se deu com o Pronaf $B$, aquele destinado às famílias mais pobres, residentes, sobretudo na região Nordeste do País.

A pesquisa coordenada pelo MDA sobre a "operacionalização da DAP conjunta, Pronaf e Pronaf Mulher" mostra que as mulheres da região Nordeste foram as principais beneficiadas com as políticas de promoção da igualdade de gênero. O Nordeste foi a única região em que, na família, mais mulheres que homens (59\%) preencheram a Declaração de Aptidão do Pronaf. Além disso, nessa região, o problema mais acentuado de acesso ao crédito apontado pelas mulheres é a falta de documentos. O Nordeste é o lugar onde houve um maior número de mulheres que tentou obter financiamento do Pronaf (MDA/NEAD, 2005).

Não se pode afirmar que esse crescimento tenha sido um resultado direto das medidas adotadas pelo governo, mas, certamente, a contribuição dessas políticas foi significativa. Condições adicionais podem ter ajudado a ampliação feminina no Pronaf, como o maior endividamento dos homens, o maior registro de homens no Serviço de Proteção ao Crédito e a maior migração masculina, especialmente no caso das áreas pobres nordestinas. Em todo caso, foi estabelecido um conjunto amplo de medidas diretamente voltadas a essa finalidade e coordenado pelas várias organizações envolvidas no processo de financiamento.

A organização social é fundamental para que populações pobres tenham acesso às políticas públicas e aos mercados. No caso do acesso ao crédito, a formação de redes de organizações que reduzam os custos de transação e a assimetria de informação mostra-se como elemento fundamental para a ampliação do acesso das famílias aos serviços financeiros (Magalhães, 2003). O acesso das mulheres ao crédito só se torna possível com medidas efetivas de ampliação do capital social dos indivíduos, no caso, o das mulheres. O contraste entre a política de acesso ao crédito e o processo de reorganização do mercado de leite mostra que é necessário um conjunto complexo de medidas para reduzir as desigualdades de gênero na agricultura familiar. 


\section{Conclusões}

Pode-se concluir com essa pesquisa que ainda se vive sob a tutela do patriarcado na área rural? $\mathrm{O}$ conceito weberiano, que define as situações nas quais "dentro de uma associação, na maioria das vezes fundamentalmente econômica e familiar, a dominação é exercida (normalmente) por uma só pessoa, de acordo com determinadas regras hereditárias fixas" (Weber, 2000) foi, durante muito tempo, a principal chave de explicação sociológica da dominação masculina na sociedade. Muitas evidências fazem crer que não. $O$ principal indício que a dominação masculina no meio rural não é mais absoluta é o fato dela não se impor mais de forma indiscutível, sem o mínimo de questionamento por parte das organizações ou das próprias mulheres.

O que falta para que as organizações sociais tenham uma contribuição efetiva na redução das desigualdades é o conhecimento das condições específicas sob as quais em cada contexto social a dominação masculina se efetiva. A divisão de papéis que atribui aos homens o relacionamento com o espaço público, da política e do mercado, e às mulheres a reclusão ao ambiente privado é um dos mais importantes fundamentos da estrutura de dominação masculina. Essa histórica condição exclui das mulheres um dos mais importantes ativos com o qual elas poderiam contar para conquistar maior autonomia social e econômica, o capital social. Ainda que cada dia mais presente na direção das organizações, a maior parte da população rural feminina está ausente não só dos espaços onde se formulam e se negociam as políticas, mas especialmente das instituições de mercado, dos espaços onde se dão os processos de capacitação e do acesso a novas tecnologias.

A perda de poder das mulheres na atividade de produção de leite é fruto não só de condições econômicas, sociais e institucionais objetivas, mas também de uma violência simbólica cotidiana que penetra na mente de cada indivíduo, tanto homens como mulheres. Por isso, é com ações transformadoras também no âmbito do capital simbólico que poderão se alcançar mudanças na condição feminina. Nas áreas rurais, um conjunto de instituições concorre para preservar as estruturas de dominação, em especial a Igreja, a escola e o estado e, no caso da agricultura familiar, os sindicatos e as cooperativas. Mas é na família que se dá o papel principal de reprodução da dominação (Bourdieu, 2005). Nos grupos sociais onde a mulher se engaja no mercado de trabalho, é estabelecida uma via externa 
de transformação das relações que vai da sociedade para o interior da família. Na agricultura familiar onde o trabalho da mulher é predominantemente agrícola, esta via é truncada, mantendo-se uma sobredeterminação das relações familiares sobre as demais relações sociais. As políticas públicas exercem influência pequena sob as regras das relações intradomiciliares. Este é um dos pilares de manutenção de relações tradicionais de gênero na área rural em cujo processo de reprodução as organizações sociais ainda não conseguem agir de forma concreta.

\section{Referências Bibliográficas}

ABRAMOVAY, Ricardo; SHRODER, Mônica; DIAS, Julio César Lima; DINIZ, João Helder; JUNQUEIRA, Rodrigo Gravina Prates; BRUSKY, Bonnie; MAGALHÃES, Reginaldo Sales. Laços financeiros na luta contra a pobreza. Annablume/Fapesp: São Paulo, 2004.

ABRAMOVAY, Ricardo; MELLO, Márcio Antonio; SILVESTRO, Milton Luiz; DORIGON, Clovis; FERRARI, Dilvan Luiz e TESTA, Vilson Marcos. Sucessão hereditária e reprodução social da agricultura familiar. In: Agricultura em São Paulo - Revista de Economia Agrícola, volume 50, número 1: São Paulo, 2003.

BECKER, Gary S. Treatise on the Family. Harvard University Press: Cambridge, 1981 - enlarged edition, 1991.

BOURDIEU. A dominação masculina. Bertrand Brasil: Rio de Janeiro, 2005.

BRUMER, Anita. Gênero e agricultura: a situação da mulher na agricultura do Rio Grande do Sul. Trabalho apresentado no XXII Congresso Internacional da Latin American Studies Association: Miami, 2000 .

BUARQUE, Cristina. A dimensão de gênero no mundo rural brasileiro contemporâneo. Seminário Internacional: Gênero no Desenvolvimento Sustentável dos Territórios Rurais. Governo do Estado do Rio Grande do Norte, Banco Mundial e IICA: Natal, 2003 (mimeo). 
CAMARANO, Ana Amélia e ABRAMOVAY, Ricardo. Êxodo rural, envelhecimento e masculinização no Brasil: panorama dos últimos 50 anos. Texto para discussão no. 621. IPEA: Rio de Janeiro, 1999.

CARNEIRO, Maria José. Camponeses, agricultores e pluriatividade. Contra Capa Livraria: Rio de Janeiro, 1998.

CELUPPI, Daniela e PANZER, Maria Helena. A gestão do trabalho a partir do olhar das mulheres agricultoras familiares. Relatório de pesquisa, RIMISP, UERGS: Francisco Beltrão, 2005 (mimeo).

DE GRANDI, Alessandra. Relações de gênero nas famílias agricultoras associadas a miniusinas de leite no estado de Santa Catarina. Dissertação de mestrado em sociologia política. Universidade Federal de Santa Catarina: Florianópolis, 1999.

ENGLAND, Paula. The separative self: androcentric bias in neoclassical assumptions. In: FERBER Marianne and NELSON, Julie. Beyond economic man: feminist theory and economics. University of Chicago Press, 1993.

ENGLAND, Paula and FOLBRE, Nancy. Gender and economic sociology. In: SMELSER, Neil J. and SWEDBERG, Richard. The handbook of Economic Sociology. Princeton University Press: Princeton and Oxford, 2005.

FERBER Marianne and NELSON, Julie. The social construction of economics and the social construction of gender. In: FERBER Marianne and NELSON, Julie. Beyond economic man: feminist theory and economics. University of Chicago Press, 1993.

HEREDIA, Beatriz Alásia de. A morada da vida: trabalho familiar de pequenos produtores do Nordeste do Brasil. Paz e Terra: Rio de Janeiro, 1979.

MACHADO, Lia Zanotta. Perspectivas em confronto: relações de gênero ou patriarcado contemporâneo? Série Antropológica, n. 284, Brasília, p.2-19, 2000.

MAGALHÃES, Reginaldo Sales. Economia, natureza e cultura: uma visão histórica e interdisciplinar dos sertanejos, dos mercados e das organizações no sertão da Bahia. Dissertação de mestrado em Ciência Ambiental. Procam, Universidade de São Paulo: São Paulo, 2005. 
MAGALHÃES, Reginaldo Sales. Habilidades sociais no mercado de leite. Relatório de pesquisa. USP/Rimisp: São Paulo, 2005.

MAGALHÃES, Reginaldo Sales; BITTENCOURT, Gilson Alceu e ABRAMOVAY, Ricardo. O papel das microfinanças no fortalecimento do empreendedorismo de pequeno porte no Brasil: propostas de política pública. Ministério do Trabalho: Brasília, 2003.

MAGALHÃES, Reginaldo Sales. A importância das instituições e das redes sociais no desempenho dos mercados financeiros. In: Anais do Congresso da Sociedade Brasileira de Economia e Sociologia Rural. Sober: Juiz de Fora, 2003.

MAIA, Cláudia J. Trabalho, família e gênero: estratégias de reprodução social camponesa no Médio Jequitinhonha. In: Mulher e Trabalho, v. 4, n. 1, p. 89-103. FEE: Porto Alegre, 2004.

MDA/NEAD. Cirandas do Pronaf para mulheres. Nead debate. MDA/NEAD: Brasília, 2005.

MENASCHE, Renata. Capinar: verbo conjugado no feminine? Notas de pesquisa sobre gênero e percepções de risco na agricultura familiar. Mneme - Revista Virtual de Humanidades, n.11, v.5, jul./set. 2004. Disponível em http://www.seol.com.br/mneme.

MENASCHE, Renata e ESCHER, Salete. Gênero e agricultura familiar: cotidiano de vida e trabalho na produção de leite. DESER E Comissão Estadual de Mulheres Trabalhadoras Rurais do Paraná: Curitiba, 1996.

MESA, Luis Eduardo Amaya. Sistematización - el funcionamiento de los bancos comunales con perspectiva de género. Proyecto FAO, Lempira Sur, Asociación ANDAR, REDNA, UICN, Fundación Arias, CANTERA: Santa Rosa de Copán, 1999.

MILKMAN, Ruth and TOWNSLEY, Eleanor. Gender and the economy. In: SMELSER, Neil J. and SWEDBERG, Richard. The handbook of Economic Sociology. Princeton University Press: Princeton and Oxford, 1994.

NELSON, Julie. Labour gender and the economic/social divide. International Labour Review. 1998. 
PANZUTTI, Nilce da Penha Migueles. Mulher rural: eminência oculta. Editora Alínea: Campinas. 2006.

PAULILO, Maria Ignez Silveira, DE GRANDI, Alessandra Bueno e SILVA, Marineide Maria. Mulher e atividade leiteira: a dupla face da exclusão. In: PAULILO, Maria Ignez Silveira e SCHMIDT, Wilson (orgs) Agricultura e espaço rural em Santa Catarina. Editora da UFSC: Florianópolis, 2003.

PAULILO, Maria Ignez Silveira. O peso do trabalho leve. In: Ciência Hoje. v. 5, n. 28, p. 64-70, jan./fev. SBPC: Rio de Janeiro, 1987.

POLLAK, Robert A. Gary Becker's Contributions to Family and Household Economics. Washington University: St. Louis, 2002.

RUTHERFORD, Stuart. The poor and their money. Institute for Development Policy and Management - University of Manchester: New Delhi, 1999.

SWEDBERG, Richard. Principles of economic sociology. Princeton University Press: Princeton, 2003.

TORRENS, João. Gênero e associativismo na agricultura familiar. CEMTR/Deser: Curitiba, 2000.

ZELIZER. A gendered division of labor. In: SWEDBERG, Richard. Economic Sociology. European Electronic Newsletter, Vol. 1, No. 3. SISWO/Institute for the Social Sciences: Amsterdam, 2000.

ZELLER, Manfred; SCHRIEDER, Gertrud; BRAUN, Joachim von; HEIDHUES, Franz. Rural finance for food security for the poor: implications for research and policy. International Food Policy Research Institute: Washington, 1997.

WEBER, Max. Economia e sociedade: fundamentos da sociologia compreensiva. Editora Universidade de Brasília: Brasília, 2000. 
